\title{
Methods to study ovarian function in monovulatory species using the cow as a model
}

\author{
Monique Tomazele Rovani ${ }^{1}$, Bernardo Garziera Gasperin ${ }^{1,2}$, Rogério Ferreira $^{3}$, Raj Duggavathi ${ }^{4}$, Vilceu \\ Bordignon ${ }^{4}$, Paulo Bayard Dias Gonçalves ${ }^{1,5}$
}

\author{
${ }^{1}$ Laboratory of Biotechnology and Animal Reproduction (BioRep), Santa Maria, RS, Brazil. \\ ${ }^{2}$ Laboratory of Animal Reproduction (ReproPel), Federal University of Pelotas, Capão do Leão, RS, Brazil. \\ ${ }^{3}$ Department of Animal Science, Santa Catarina State University, Chapecó, SC, Brazil. \\ ${ }^{4}$ Department of Animal Science, McGill University, Sainte Anne de Bellevue, QC, Canada.
}

\begin{abstract}
In this review, we discuss the utility of the cow as an in vivo model to study the regulation of ovarian functions in monovular species. It is increasingly becoming clear that besides endocrine control, locally produced factors play pivotal roles during dominant follicle selection, oocyte maturation, ovulation and luteolysis. Although in vitro culture systems have been used to study these processes, definitive understanding the interactions between endocrine and local factors requires appropriate in vivo models. Most of the experimental approaches to study ovarian functions in vivo in large animals are based on the use of ultrasonography and considerable progress in this field has been made during the last thirty years. It has been shown that cows are an excellent model to collect samples (e.g., follicular fluid, granulosa cells, oocytes) from live animals at specific stages of follicular development in order to study mechanisms of intrafollicular factors in a physiological endocrine environment. In addition to support fundamental studies, the cow model has contributed immensely to the refinement of assisted reproductive technologies, which are now widely used not only in farm animals but also in humans.
\end{abstract}

Keywords: follicle development, ovulation, luteolysis, in vivo, cattle.

\section{Introduction}

Successful development of a healthy ovarian follicle culminating in ovulation and subsequent formation of the corpus luteum (CL) is essential for fertility. This process involves various types of specialized cells within the ovaries, which in response to gonadotropin signaling produce steroid hormones and other local factors. Granulosa cells have a pivotal role in maintaining the communication between the oocyte and the somatic cells including the theca layer, which is necessary for the successful maturation of the oocyte. The importance of local factors in the selection of the dominant follicle, ovulation, luteinization and oocyte meiotic resumption has long been recognized. Also, regression of the $\mathrm{CL}$ requires intraluteal factors in addition to the action of the endometrial prostaglandin F2 alpha (PGF2 $\alpha$ ). However, detailed characterization of factors and pathways involved in granulosa function remains a challenge for ovarian biologists. Various experimental models have been used to investigate the mechanisms regulating ovarian function and fertility, but they all have advantages and limitations.

Our current knowledge about the molecular mechanisms coordinating granulosa cell functions is mainly based on in vitro cell culture approaches or using rodents as in vivo models (Richards, 1975; Richards and Hedin, 1988; Matzuk et al., 2002; Hunzicker-Dunn and Maizels, 2006; Pépin et al., 2007; Binelli and Murphy, 2009; Menon et al., 2013; Sahmi et al., 2014). While granulosa cell cultures have been used to study the molecular regulatory pathways, there are physiological dissimilarities between granulosa cells in vivo and in vitro. For example, granulosa cells maintained in various culture systems were shown to luteinize and fail to maintain estradiol synthesis (Channing and Ledwitz-Rigby, 1975; Silva and Price, 2000). Indeed, with the current culture systems, it is not possible to recapitulate in vitro follicular processes such as antrum formation and ovulation. In mice, the development of antral follicles occurs in a wave-like pattern similarly to cattle and humans, but multiple follicles $(\sim 10)$ are selected to reach ovulatory size of $>500 \mu \mathrm{m}$ in diameter (Jaiswal et al., 2009). The main advantage of using the mouse model is its amenability for genetic manipulations, including gene targeting in the ovary. However, because of their small body and ovary sizes, sample size is a limitation for technologies like chromatin immunoprecipitation, hormone assays and analyses of metabolites. Most importantly, it is often questioned whether results obtained in polyovulatory species can be translated to monovulatory species, e.g., bovine and human.

Cows and mares have been preferred animals to study ovarian physiology in vivo in monovular species. Indeed, among other domestic animals, cattle and horses are considered more representative models for the study of human ovarian functions (Adams et al., 2012; Ginther, 2012). Using transrectal ultrasonography, follicle development can be monitored, and follicle deviation and ovulation can be accurately determined in both species. More importantly, mechanistic studies can be performed in vivo through modification of the microenvironment of a specific follicle using ultrasound-guided intrafollicular injection (IFI), as first described by Kot et al. (1995). 
The main objectives in this review article are to: 1) describe advantages and limitations of in vivo models to study ovarian function in monovulatory species; 2) discuss our experience using cows as the animal model for the study of ovarian functions in vivo including follicle development, ovulation, oocyte maturation, luteogenesis and luteolysis; and 3) integrate some of the knowledge obtained from studies on monovulatory animal models in vivo, especially from Bos taurus beef cows.

\section{Protocols used to study ovarian functions in cows}

\section{Induction of a new follicular wave and ovulation}

Follicular development is very dynamic, especially during gonadotropin dependent phase, consisting of growing, static and regression phases. Even though follicles appear virtually similar when they are in their late growing, static or early regression phases, their steroidogenic ability, oocyte quality and gene expression are different (Singh et al., 1998; Vassena et al., 2003; Evans et al., 2004; Douville and Sirard, 2014; Hatzirodos et al., 2014). Therefore, studies investigating mechanisms of folliculogenesis need to emphasize the exact phase of follicular development at the time of sample collection for steady-state molecular analyses. The best way to ensure a follicle is healthy is by monitoring its growth for multiple days. The induction of estrus and ovulation represents the most physiological approach to induce the emergence of a follicular wave in cattle. Two doses of PGF2 $\alpha$ analogue given $12 \mathrm{~h}$ apart have been used to induce estrus in cyclic cows (Bergfelt et al., 1994). After estrus detection, ovulation is confirmed by at least two consecutive transrectal ultrasound evaluations and the emergence of a new follicular wave is monitored. Other protocols are also suited for the purpose as described below.

Ultrasound-guided follicular ablation along with luteolysis induced by a single dose of PGF2 $\alpha$ is another way of inducing a new follicular wave. Circulating concentrations of FSH increase within $24 \mathrm{~h}$ after the follicular ablation, leading to emergence of a new follicular wave within 2 days (Bergfelt et al., 1994). However, we have observed that large follicles sometimes reappear $24 \mathrm{~h}$ after ablation forming follicle hematomas, which has also been described by Bergfelt et al. (1994). As the impact of these hematomas on health and endocrine profile of the follicle in question cannot be predicted, it is recommended to remove such cows from the experiments.

Progesterone and estradiol have also been used to synchronize follicular waves in cattle since they can induce the regression of most antral follicles present in the ovary at the time of treatment (Siqueira et al., 2009). Intravaginal progesterone devices are inserted along with i.m. administration of estradiol benzoate and PGF2 $\alpha$. Five to nine days later, the progesterone devices are removed and follicular dynamics is followed by daily ultrasound examination until the growing follicles of the new follicular wave reach the target diameter to perform intrafollicular injection or ovariectomy. Follicles are monitored at least three times before intrafollicular treatment to confirm that only new growing follicles and no aged follicles are present in the ovaries (Gasperin et al., 2012). Despite less timeconsuming in comparison to estrus detection-based protocols, many cows are usually removed from the experiment because large follicles fail to regress after progesterone exposure. In a recent study, we have successfully identified the dominant follicle in 24 out of 25 synchronized cows by combining the steroid-based protocol with aspiration of follicles larger than $8 \mathrm{~mm}$ (follicles from previous waves) at the expected time of follicular emergence (around day 4 after estradiol injection and progesterone device insertion; data not published).

To study ovulation-related events, hormonal protocols along with ultrasound monitoring of ovarian dynamics are preferred because they allow better control of follicle maturation. Intravaginal progesterone releasing devices are used to prevent the endogenous LH surge, which is otherwise difficult to predict. Prostaglandin F2 $\alpha$ treatment along with removal of the progesterone device ensure that dominant follicles are responsive to ovulatory stimulus. An i.m. dose of GnRH induces the LH surge 1 to $3 \mathrm{~h}$ after treatment (Komar et al., 2001), which triggers the complex process of follicular rupture, luteinization and oocyte meiotic resumption. In this regard, it is important to consider that $\mathrm{GnRH}$ induces a transitory increase in LH that lasts for $6 \mathrm{~h}$ whereas after porcine $\mathrm{LH}(\mathrm{pLH})$ injection its levels remain elevated for about $20 \mathrm{~h}$ (Behrouzi et al., 2016). If the research goal is to assess oocyte meiotic resumption, FSH can be used before $\mathrm{GnRH}$ or $\mathrm{LH}$ treatment to increase the number of follicles per cow (Barreta et al., 2008; Siqueira et al., 2012).

\section{Intrafollicular injection (IFI)}

The IFI procedure was first described by Kot $e t$ al. (1995), who injected hCG into large follicles of the first follicular wave on day 8 of the estrus cycle and induced ovulation in 5 out of 5 cows. Our group has adapted the intrafollicular injection system, which comprises two needles. The external needle ( $21 \mathrm{~g} 1 \frac{1}{2}$ ") is attached to a biopsy guide to cross the vaginal wall, peritoneum and ovarian stroma. The internal needle (25 g $31 / 2 ")$ is used to penetrate the follicular wall and perform the intrafollicular treatment. An ovum pick up needle attached to a Hamilton syringe is used to guide the internal needle and to inject the appropriate amount of the treatment. To perform the injection, the ovary is positioned in such a way that the outer needle enters the ovarian stroma until its tip becomes visible on the ultrasound monitor approximately $2 \mathrm{~mm}$ away from the wall of the follicle of interest. At this point, the inner needle is pushed forward until the needle tip is seen inside the follicular antrum. Treatments are injected and swirling of the injected fluid indicates that the injection has been performed correctly. The volume to be injected is usually around $10 \%$ of the total follicular fluid volume, which can be estimated by a the linear 
regression equation (Ferreira et al., 2007). To confirm the success of the procedure, transrectal ultrasonography should be performed by about $2 \mathrm{~h}$ after IFI. Any cow with follicles reduced in diameter by greater than $2 \mathrm{~mm}$, a sign of follicular fluid leakage, should be removed from the experiment. We have obtained $80-100 \%$ ovulation rates in control follicles (saline-injected), which confirms that this procedure does not interfere with the normal ovulation process (Ferreira et al., 2007; Haas et al., 2016).

The main advantage of IFI is the possibility of studying mechanisms under physiological endocrine environment with cellular interactions among granulosa cells, theca cells and the oocyte. Furthermore, oocytes, follicular fluid and granulosa cells can be collected from individual follicles under epidural anesthesia using an adapted ovum pick up system, without the need to euthanize animals (Beg et al., 2001; Arashiro et al., 2013; Sanchez et al., 2014). Based on our experience, IFI is an excellent method to manipulate ligand/receptor signaling in a follicle of known developmental status without interfering with such signals in other follicles or tissues. Also, if FSH is used to increase follicular numbers as described above, follicles from one ovary can be injected with vehicle (control) and follicles from the contralateral ovary injected with the treatment compound. The main advantage of this protocol is that both ovaries remain under the same endocrine environment. Interestingly, IFI in cows can be considered as an alternative approach to conditional gene targeting in mice. Nevertheless, the main limitation of IFI is that intrafollicular treatments are restricted to pharmacological regulators such as agonists and antagonists of ligands or receptor, which can modulate the signaling process of interest. Although, IFI could be used to inject viral vectors for the delivery of small interfering RNAs (siRNA) for specific gene targeting, this procedure has not yet been tested.

\section{Examples of the utility of the cow in the study of ovarian functions}

Over the past ten years, our research group has conducted various studies investigating ovarian functions in vivo using cows as the animal model for monovulatory species. Follicular development in cattle occurs in waves and only one follicle is selected, whereas subordinate follicles undergo atresia, similar to what is observed in humans (Baerwald et al., 2003). To characterize the molecular mechanisms of dominant follicle selection and atresia of subordinate follicles, we have used ovariectomy by colpotomy at specific stages of the follicular wave (Drost et al., 1992). The same approach was previously used by Evans and Fortune (1997). Granulosa cells, theca cells and follicular fluid of the two largest follicles were used for characterization of molecular pathways. Moreover, intrafollicular injection of ligands into the largest or the second largest follicle followed by transrectal ultrasonography or ovariectomy at specific time-points after treatment has been performed to investigate the role of local factors on follicular development and atresia (Ferreira et al., 2011a; Gasperin et al., 2012; Barreta et al., 2015). As an alternative to ovariectomy, ultrasound-guided follicular aspiration may be used to recover follicular fluid and granulosa cells from individual follicles (Sanchez et al., 2014). This technique has the advantage of allowing the reutilization of the cows in additional studies or their return to the farm breeding/production program.

\section{Follicular deviation}

Ovulation is followed by a dramatic decrease in estradiol concentrations and an increase in FSH, inducing the emergence of the first follicular wave in about $24 \mathrm{~h}$ after follicle rupture. The day of follicular wave emergence (usually on day 1 of the cycle) is designated as day 0 of the wave and is retrospectively identified as the last day on which the dominant follicle was 4 to $5 \mathrm{~mm}$ in diameter (Evans and Fortune, 1997). Ovaries are then examined by daily transrectal ultrasonography and all follicles larger than $5 \mathrm{~mm}$ are drawn using 3 to 5 virtual slices of the ovary (Jaiswal et al., 2004). Cows are randomly assigned to be ovariectomized at days 2,3 or 4 of the follicular wave when the sizes of the largest and second largest follicle are similar (day 2 of the wave), slightly different (day 3 ) or markedly different (day 4; Fig. 1A). This follicular deviation model is suitable for investigating roles of ligands and receptors before, at the expected time, and after follicular deviation. Daily ultrasound monitoring of follicular growth allows the precise identification of healthy and atretic follicles to be sampled for molecular phenotyping. Furthermore, markers of follicular dominance such as estradiol concentration in the follicular fluid and transcript levels of LHCGR and CYP19A1 in granulosa cells are used to confirm the follicular status (Evans and Fortune, 1997; Evans et al., 2004; Mihm et al., 2006; Gasperin et al., 2014). It has been reported that by day 6 (considering day 1 as the day when two or more follicles greater than $4 \mathrm{~mm}$ in diameter were observed), under high progesterone levels, the dominant follicle shows early signs of atresia such as decreased estradiol concentrations, and increased percentage of apoptotic cells (Valdez et al., 2005).

\section{Follicular codominance}

Another useful approach to study the mechanisms involved in follicular dominance is by inducing two follicles to become codominants. For this, animals are treated with $2 \mathrm{mg}$ of FSH i.m. every 12 for $48 \mathrm{~h}$ when follicles of the first wave are $6 \mathrm{~mm}$ in diameter, which allows the development of codominant follicles (Rivera and Fortune, 2001). Working with beef cows, we have observed that codominant follicles can be induced with slightly higher doses of FSH (four doses $12 \mathrm{~h}$ apart: 30, 30, 20 and $20 \mathrm{mg}$ ), whereas control animals receive saline at the same time-points. Blood samples can be collected at the same time of the treatments and ovaries collection. The two largest follicles can be collected at specific time-points, such as 
$12 \mathrm{~h}$ after the last dose of FSH or saline (day 4; Fig. 1B; Ilha et al., 2015). Using this model, it is possible to study the molecular signals induced by FSH treatment in follicular cells, compare dominant, codominant and subordinated follicles, as well as compare the levels of proteins diluted in the follicular fluid and plasma.
DEVIATION MODEL

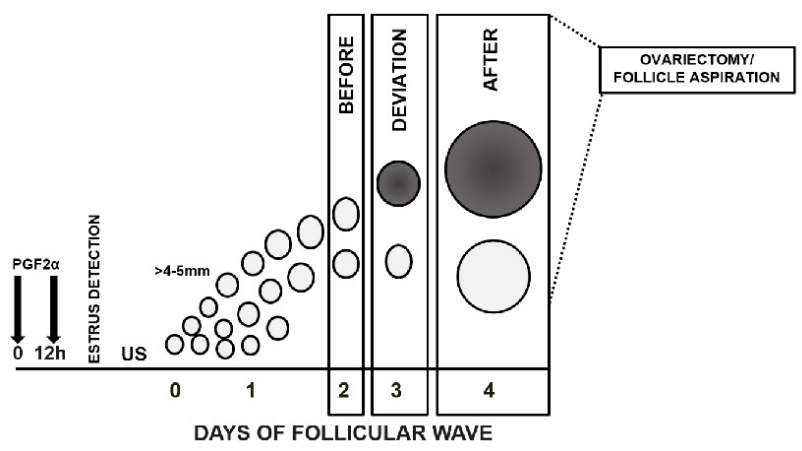

A

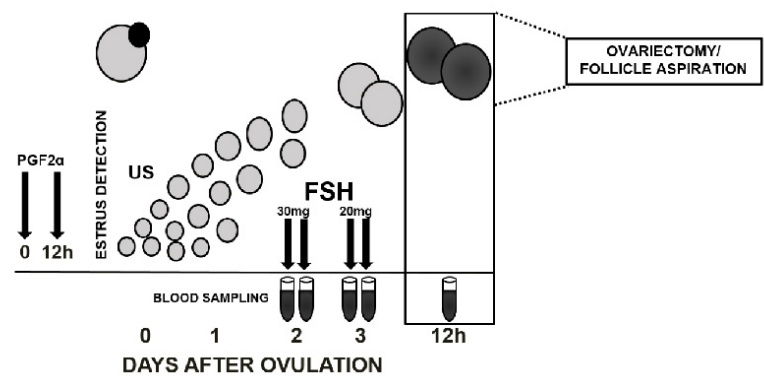

Figure 1. Schematic representation of in vivo experimental models of follicular deviation and codominance in cattle. A) Follicular deviation model: follicular fluid, granulosa and theca cells are collected by ovariectomy on days 2 (before), 3 (at the expected moment) or 4 (after deviation) of follicular wave to recover the two largest follicles. B) Follicular codominance model: granulosa cells are collected by ovariectomy $12 \mathrm{~h}$ after four doses of FSH (30, 30, 20 and $20 \mathrm{mg}, 12 \mathrm{~h}$ apart) or saline administered (i.m.) twice a day starting on day 2 after ovulation. PGF2 $\alpha$ : prostaglandin F2 $\alpha$; FSH: follicle-stimulating hormone; US: ultrasound. Tubes represent blood sampling time-points.

\section{Follicular development and atresia}

The intrafollicular injection approach has been used to study the function of local growth factors during follicular deviation. Based on our experience, follicles beyond $5 \mathrm{~mm}$ can be injected and monitored. Using this technique, it has been possible to explore the mechanisms involved in follicle development and atresia. For instance, the intrafollicular injection of insulin-like growth factor 1 (IGF-1) in the second largest follicles (when the largest follicle reached 8.5 $\mathrm{mm}$ ) increased estradiol secretion (Ginther et al., 2004), proving that IGF-1 is a pivotal factor for follicle development. Using a similar approach, our group demonstrated that second largest follicles treated with angiotensin II (Ang II) or Ang II type 2 receptor (AGTR2) agonist continued to grow at a rate similar to the dominant follicle for $24 \mathrm{~h}$, suggesting that Ang II stimulates follicle development (Ferreira et al., 2011a). The fact that local factors are able to change the fate of subordinate follicles during follicle deviation demonstrates the suitability of this experimental paradigm in the characterization of novel regulatory factors and their molecular mechanisms.

Likewise, IFI in healthy growing follicles can be used to study ligands, receptors and intracellular pathways crucial to follicle development, steroidogenesis and cells differentiation (Fig. 2A). Treatments have also been performed in the future dominant follicle during deviation (Ferreira et al., 2011a; Gasperin et al., 2012) or in differentiated dominant follicles (Lv et al., 2009; Haas et al., 2016). Ultrasound monitoring and ovariectomy allow for exploring the effect of treatment on follicular development, steroidogenesis and gene expression. We injected fulvestrant, an antagonist of estradiol receptors, or vehicle in the future dominant follicle and collected treated follicles $12 \mathrm{~h}$ later to study some genes regulated by estradiol in granulosa cells (Ferreira et al., 2011b; Rovani et al., 2014).

Recently, our group adopted the simultaneous extraction of RNA, DNA and protein from the same sample using commercial kits (Gasperin et al., 2015; Ilha et al., 2015; Rosa et al., 2016). This approach allows the evaluation of candidate genes and proteins at both transcriptional and translational levels in the same samples (Fig. 2B). Furthermore, posttranslational modifications can be assessed, allowing identification of phosphorylated forms, precursors and mature forms of cleaved proteins. Based on our experience, from a single $6 \mathrm{~mm}$ follicle it is possible to obtain enough RNA to evaluate hundreds of genes, and protein to run three to five immunoblots (loading $\sim 25$ $\mu \mathrm{g}$ of protein from each sample). Using this approach, we observed that the signal transducer and activator of transcription 3 (STAT3) is only activated (phosphorylated) in day 4 subordinate (atretic) follicles concomitantly to the appearance of cleaved caspase 3 (Gasperin et al., 2015). However, STAT3 was not activated in FSH-stimulated co-dominant follicles (Ilha et al., 2015), which suggests a potential role in granulosa cells death. 

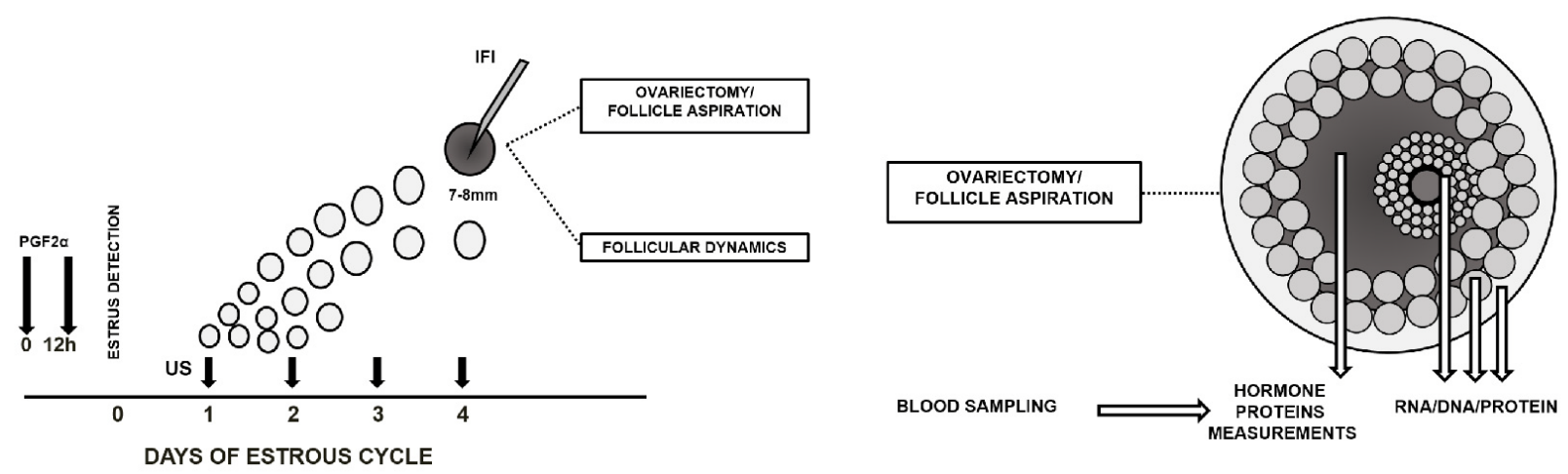

Figure 2. Schematic representation of in vivo intrafollicular treatment and collection of follicle samples. A) Intrafollicular treatment: a new follicular wave is induced and when the largest follicle reaches 7-8 $\mathrm{mm}$, the treatment is intrafollicularly injected into this largest follicle. Follicular dynamics is performed by ultrasound or follicular cells and follicular fluid are retrieved by follicular aspiration or after ovariectomy. B) Samples collection: collection of oocytes, follicular fluid, granulosa and theca cells to simultaneously extract RNA, DNA and protein from the same follicle. Follicular fluid and blood samples are destined to hormone/proteins measurements. PGF2 $\alpha$ : prostaglandin F2 $\alpha$; US: ultrasound; IFI: intrafollicular injection.

\section{LH signaling in the periovulatory period}

Fully differentiated dominant follicles can be used to study LH targets in granulosa and theca cells in vivo. Large amount of follicular fluid samples can also be recovered to characterize secreted factors during ovulation. A traditional model consists of inducing a new follicular wave to obtain preovulatory follicles larger than $12 \mathrm{~mm}$. GnRH analogues (e.g., $100 \mu \mathrm{g}$ of gonadorelin acetate) are administered to induce the $\mathrm{LH}$ surge and follicles are obtained between 0 to $24 \mathrm{~h}$ after GnRH treatment (Fig. 3A). An acute decrease in granulosa cells estradiol synthesis is observed $3 \mathrm{~h}$ postGnRH, thus estradiol concentrations in follicular fluid can be measured to confirm the treatment efficacy.

At specific time-points after $\mathrm{GnRH}$ treatment, the ovary bearing the preovulatory follicle is collected by colpotomy, transported to the lab and the follicle is identified and dissected from the ovary. After that, it is possible to separate follicular fluid, oocyte, granulosa and theca cells to perform the in vitro studies. A piece of the follicular wall can be fixed for histological evaluation of ovulation-related changes in the extracellular matrix and granulosa/theca cells organization. Furthermore, changes in follicular environment associated to oocyte capacitation, resumption of meiosis and luteinization can be investigated. Another possibility is to collect preovulatory follicles through ovariectomy and perform in vitro studies (Komar et al., 2001). This model is an alternative to intrafollicular injection and allows submitting follicular cells to several treatments in vitro, despite losing the endocrine environment.

\section{Inhibition of LH-induced signaling}

During ovulation, the IFI technique has been used to test the effect of antagonists of locally produced factors on ovulation. The intrafollicular treatment is followed by ultrasound evaluations to confirm ovulation or aspiration of follicular fluid to evaluate local secreted factors (Peters et al., 2004). Samples may also be used to study molecular events in granulosa and theca cells.

Using this model, it was demonstrated that prostanoids are crucial during the ovulatory process, since intrafollicular injection of inhibitors of their synthesis inhibited ovulation and downregulated genes involved in extracellular matrix remodeling (Peters et al., 2004; Li et al., 2009). In addition, angiotensin II was shown to be essential during the early stage of ovulation in cattle, since intrafollicular injection of antagonist (saralasin) of the receptors AGTR1 and AGTR2 abrogated ovulation when performed before estrus onset or until $6 \mathrm{~h}$ after GnRH injection (Ferreira et al., 2007). In the same study, it was demonstrated that Ang II action during ovulation is mediated by the AGTR2 receptor.

\section{Ovulation-related events}

Three different approaches have been used by our group and others to study ovulation-related events in cattle. First, since the dominant follicles in Bos taurus taurus cows become LH responsive when they reach 12 $\mathrm{mm}$ in diameter (Sartori et al., 2001), cows can be treated with GnRH when the dominant follicle of the synchronized follicular wave reaches this size and then collected at specific time-points after treatment (Santos et al., 2011; Rosa et al., 2016). For instance, using dairy cows as an in vivo model, it was recently demonstrated that GnRH- and LH-induced ovulations are different in many aspects, especially regarding regulation of transforming growth factors $\beta$ (TGF $\beta$ ) members (Behrouzi et al., 2016). Follicles from LH-treated cows had increased BMP15, GDF9 and TGF $\beta 1$ mature proteins and LHCGR, PTGS2 and PGR mRNA expression compared to GnRH-treated cows.

Injection of agonists or antagonists into single pre-ovulatory follicles followed by $\mathrm{GnRH}$ treatment allows investigation of LH-induced factors involved in the ovulatory cascade (Ferreira et al., 2007; Rosa et al., 
2016). Superovulation followed by multiple intrafollicular injections and ovariectomy enables examination of factors involved in meiotic resumption after GnRH challenge (Barreta et al., 2008).

\section{Oocyte and meiotic resumption}

Studying oocyte maturation in monovular species requires a large number of animals. As an alternative, conventional superovulation protocols can be used to increase the number of growing follicles. For this, the number of follicles is determined by transrectal ultrasonography on the day before intrafollicular injection (day 9 of the progesterone treatment). To facilitate the intrafollicular injection procedure and eliminate follicles non-responsive to LH (Sartori et al., 2001), all follicles with diameter between 5 to $11 \mathrm{~mm}$ are aspirated using a vacuum pump, leaving no more than the three largest follicles in each ovary (Siqueira et al., 2012). On the afternoon of the day of intrafollicular injection (day 10), the intravaginal progesterone device is removed, each ovary is examined by transrectal ultrasonography, and all follicles $>12 \mathrm{~mm}$ in diameter are subjected to intrafollicular injections (Barreta et al., 2008). To confirm the success of the procedure, cows are evaluated $2 \mathrm{~h}$ after intrafollicular injection and follicles that have a reduction in diameter greater than $2 \mathrm{~mm}$, suggesting follicular fluid leakage, are removed from the experiments. Using this model, our group demonstrated that progesterone mediates the resumption of meiotic progression induced by the LH surge in cattle (Siqueira et al., 2012).

Approximately $90 \%$ of oocytes recovered from saline injected follicles were at germinal vesicle breakdown (GVB) or metaphase I (MI) stages at $12 \mathrm{~h}$ after GnRH injection (Barreta et al., 2008; Siqueira et al., 2012). This confirmed that intrafollicular injection did not affect meiotic resumption. Therefore, IFI is a useful tool to study bovine oocyte nuclear maturation. However, the cost of superovulation protocols and the fact that some cows do not respond to the protocol must be taken into account when performing oocyte maturation experiments in vivo. One possibility to increase the number of oocytes per cow would be the intrafollicular injections of multiple oocytes as performed in mares by Goudet et al. (1997). In that study, in vivo oocyte maturation rates after injecting 3 to 9 cumulus oocyte complexes (COCs) into preovulatory (30-36 mm) follicles were similar to in vitro maturation. Recently, we and others (Kassens et al., 2015; Spricigo et al., 2016) have tested the feasibility of injecting COCs into dominant follicles and confirmed that this technology can also be applied in cattle. This model in cattle still needs further validation to ensure that one preovulatory follicle is able to maintain injected-oocytes viability. Recovery rates and embryo development rates need to be improved to allow the adoption of intrafollicular oocyte transfer (IFOT) under field conditions (Spricigo et al., 2016).

\section{Luteogenesis and luteolysis}

Cows are also an excellent animal model to investigate CL development and regression in vivo. The
CL forms from the remnant of an ovulated follicle after LH surge. The steroidogenic pathway is dramatically upregulated, and the progesterone becomes the main steroid produced by luteinized granulosa (large steroidogenic cells) and theca cells (small steroidogenic cells) after ovulation (Donaldson and Hansel, 1965). The CL becomes responsive to PGF2 $\alpha$ at about day 5 after ovulation and at day 10 this temporary gland shows full activity and produces large amounts of progesterone. Luteolysis occurs at days 16-17 of bovine estrous cycle and is classified as functional luteolysis (reduction of steroidogenesis), and morphological luteolysis (CL tissue degradation; Davis and Rueda, 2002).

A methodology to obtain CL samples was proposed by Shirasuna et al. (2012). After observing the estrus, the ovulation is confirmed by ultrasound inspection two days later. One day before ovariectomy, cows are monitored by ultrasound to confirm the presence of a CL. The ovaries are collected at day 5 (growing CL) and between days 10 and 12 (full steroidogenic CL) of estrous cycle.

A well-established in vivo model of luteolysis involves administration of PGF $2 \alpha$ and collection of samples at specific time-points post injection to characterize local factors and signaling pathways involved in steroidogenesis, cell proliferation and cell death (Juengel et al., 1993; Shirasuna et al., 2012). Histological analyses and progesterone profiles from treated animals can confirm the expected phase of CL and the success of PGF2 $\alpha$ treatment. Cows on day 10 of the estrus cycle are treated with a luteolytic dose of PGF $2 \alpha$ and the ovariectomies are performed during functional luteolysis $(0,2$ and $12 \mathrm{~h}$ after treatment) and morphological luteolysis ( 24 and $48 \mathrm{~h}$ after treatment). The CLs are dissected with the aid of forceps and blades, and samples are obtained for mRNA, protein and histological analysis. Additionally, serum progesterone concentration is evaluated in each animal before and after treatments to confirm the luteolysis model (Fig. 3B).

The main advantage of the CL development and lysis model is the possibility of taking the samples at the exact expected time of CL development or after PGF $2 \alpha$ treatment in a physiological environment. Additionally, compared to the aforementioned models, larger amount of sample can be collected, allowing simultaneous mRNA, protein and histological studies. In contrast to experiments involving follicles, it is not possible to collect CL samples without performing the ovariectomy. On the other hand, the amount of tissue collected from each animal allows many different approaches to investigate local factors during luteolysis.

The collection of PGF-treated CLs does not allow evaluating the direct effect of a specific factor. The technique of implantation of microdialysis (MDS) system into the CL (Blair et al., 1997; Ohtani et al., 1998) or intraluteal injection (Shirasuna et al., 2006) could be adopted to release treatments directly into the CL. However, the surgery is extremely invasive and usually the experiments require a great number of animals in the case of the MDS system fails. An alternative is to perform biopsies in the same animal at multiple time-points, but it requires specific tools and a very well trained professional (Atli et al., 2012). 
OVULATION MODEL

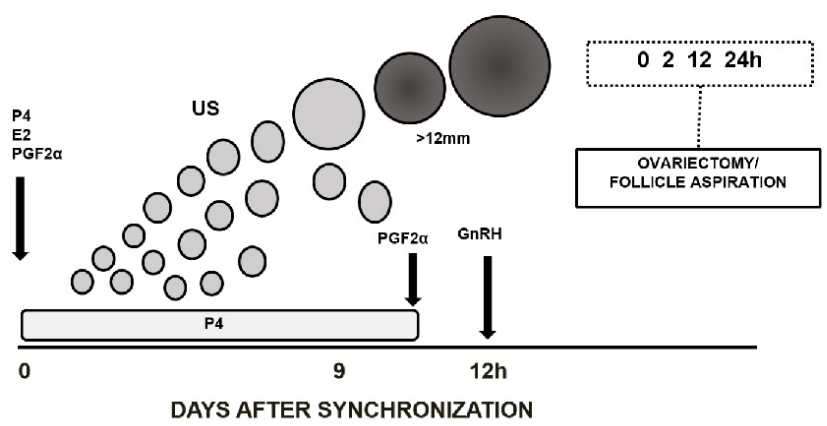

CORPUS LUTEUM MODEL

B

Figure 3. Schematic representation of in vivo experimental models of ovulation and for the study of corpus luteum. A) Ovulation model: a new follicular wave is induced to obtain preovulatory follicles larger than $12 \mathrm{~mm}$. GnRH analogues are i.m. administered and follicles are obtained between 0 to $24 \mathrm{~h}$ after treatment. B) Corpus luteum model: blood samples and CLs are collected from separate groups of cows before and 2, 12, 24, and $48 \mathrm{~h}$ after PGF treatment on day 10 of the estrous cycle. PGF2 $\alpha$ : prostaglandin F2 $\alpha$; FSH: follicle-stimulating hormone; US: ultrasound; IFI: intrafollicular injection; P4: progesterone; E2: estradiol. Tubes represent blood sampling time-points.

\section{Conclusions}

Cows are a valuable animal model to study ovarian functions of monovulatory species in vivo under physiological endocrine environment and intact follicular cell communication through autocrine and paracrine signaling. Several in vivo experimental techniques are now available, and some are wellestablished and have been used to study the regulation of gene expression and intracellular signaling during follicle deviation, dominance and ovulation. Using these recently developed techniques, including follicular aspiration, daily follicular fluid collection and CL biopsies, it is now possible to perform repeated sample collections from the ovaries of live animals without the need of ovariectomize or euthanize valuable cows used in research. However, conduction of functional studies in live cows is still restricted to intrafollicular injection of receptors agonists or antagonists. A method that allows for specific gene manipulations in vivo during follicular development of monovulatory species remains to be established and validated.

\section{Acknowledgments}

The authors disclosed receipt of the following financial support for the research, authorship, and/or publication of this article: Supported by CNPq, CAPES and FAPERGS from Brazil, and the Natural Sciences and Engineering Research Council (NSERC) of Canada. MTR was supported by a scholarship from the Brazilian Council of Scientific and Technological Development (CNPq) as a visiting research trainee at McGill University.

\section{References}

Adams GP, Singh J, Baerwald AR. 2012. Large animal models for the study of ovarian follicular dynamics in women. Theriogenology, 78:1733-1748.

Arashiro E, Palhao M, Wohlres-Viana S, Siqueira L, Camargo L, Henry M, Viana J. 2013. In vivo collection of follicular fluid and granulosa cells from individual follicles of different diameters in cattle by an adapted ovum pick-up system. Reprod Biol Endocrinol, 11:73, 8 pp.

Atli MO, Bender RW, Mehta V, Bastos MR, Luo W, Vezina CM, Wiltbank MC. 2012. Patterns of gene expression in the bovine corpus luteum following repeated intrauterine infusions of low doses of prostaglandin F2alpha. Biol Reprod, 86:130-113.

Baerwald AR, Adams GP, Pierson RA. 2003. Characterization of ovarian follicular wave dynamics in women. Biol Reprod, 69:1023-1031.

Barreta MH, Oliveira JFC, Ferreira R, Antoniazzi AQ, Gasperin BG, Sandri LR, Goncalves PBD. 2008. Evidence that the effect of angiotensin II on bovine oocyte nuclear maturation is mediated by prostaglandins E2 and F2 $\alpha$. Reproduction, 136:733-740.

Barreta MH, Gasperin BG, Ferreira R, Rovani M, Pereira GR, Bohrer RC, de Oliveira JF, Gonçalves PBD. 2015. The components of the angiotensin-(1-7) system are differentially expressed during follicular wave in cattle. J Renin Angiotensin Aldosterone Syst, 16:275-283.

Beg M, Bergfelt D, Kot K, Wiltbank M, Ginther O. 2001. Follicular-fluid factors and granulosa-cell gene expression associated with follicle deviation in cattle. Biol Reprod, 64:432-441.

Behrouzi A, Colazo MG, Ambrose DJ. 2016. Alterations in bone morphogenetic protein 15, growth differentiation factor 9 , and gene expression in granulosa cells in preovulatory follicles of dairy cows given porcine LH. Theriogenology, 85:1249-1257.

Bergfelt DR, Lightfoot KC, Adams GP. 1994. Ovarian synchronization following ultrasound-guided transvaginal follicle ablation in heifers. Theriogenology, 42:895-907.

Binelli M, Murphy BD. 2009. Coordinated regulation of follicle development by germ and somatic cells. Reprod Fertil Dev, 22:1-12.

Blair RM, Saatman R, Liou SS, Fortune JE, Hansel W. 1997. Roles of leukotrienes in bovine corpus 
luteum regression: an in vivo microdialysis study. Proc Soc Exp Biol Med, 216:72-80.

Channing CP, Ledwitz-Rigby F. 1975. Methods for assessing hormone-mediated differentiation of ovarian cells in culture and in short-term incubations. Methods Enzymol, 39:183-230.

Davis JS, Rueda BR. 2002. The corpus luteum: an ovarian structure with maternal instincts and suicidal tendencies. Front Biosci, 7:d1949-1978.

Donaldson L, Hansel W. 1965. Histological study of bovine corpora lutea. J Dairy Sci, 48:905-909.

Douville G, Sirard MA. 2014. Changes in granulosa cells gene expression associated with growth, plateau and atretic phases in medium bovine follicles. $J$ Ovarian Res, 7:50.

Drost MD, Savio JD, Barros CM, Badinga L, Thatcher WW. 1992. Ovariectomy by colpotomy in the cow. J Am Vet Med Assoc, 200:337-342.

Evans ACO, Fortune JE. 1997. Selection of the dominant follicle in cattle occurs in the absence of differences in the expression of messenger ribonucleic acid for gonadotropin receptors. Endocrinology, 138:2963-2971.

Evans ACO, Ireland JLH, Winn ME, Lonergan P, Smith GW, Coussens PM, Ireland JJ. 2004 Identification of genes involved in apoptosis and dominant follicle development during follicular waves in cattle. Biol Reprod, 70:1475-1484.

Ferreira R, Oliveira JF, Fernandes R, Moraes JF, Gonçalves PB. 2007. The role of angiotensin II in the early stages of bovine ovulation. Reproduction, 134:713-719.

Ferreira R, Gasperin B, Rovani M, Santos J, Barreta M, Bohrer R, Price C, Goncalves PB. 2011a Angiotensin II signaling promotes follicle growth and dominance in cattle. Endocrinology, 152:4957-4965.

Ferreira R, Gasperin B, Santos J, Rovani M, Santos RA, Gutierrez K, Oliveira JF, Reis AM, Goncalves PB. 2011b. Angiotensin II profile and mRNA encoding RAS proteins during bovine follicular wave. J Renin Angiotensin Aldosterone Syst, 12:475-482.

Gasperin BG, Ferreira R, Rovani MT, Santos JT, Buratini J, Price CA, Goncalves PB. 2012. FGF10 inhibits dominant follicle growth and estradiol secretion in vivo in cattle. Reproduction, 143:815-823.

Gasperin BG, Ferreira R, Rovani MT, Bordignon V, Duggavathi R, Buratini J, Oliveira JFC, Gonçalves PBD. 2014. Expression of receptors for BMP15 is differentially regulated in dominant and subordinate follicles during follicle deviation in cattle. Anim Reprod Sci, 144:72-78.

Gasperin BG, Rovani MT, Ferreira R, Ilha GF, Bordignon V, Gonçalves PBD, Duggavathi R. 2015. Functional status of STAT3 and MAPK3/1 signaling pathways in granulosa cells during bovine follicular deviation. Theriogenology, 83:353-359.

Ginther OJ, Bergfelt DR, Beg MA, Meira C, Kot K. 2004. In vivo effects of an intrafollicular injection of insulin-like growth factor 1 on the mechanism of follicle deviation in heifers and mares. Biol Reprod, 70:99-105. Ginther OJ. 2012. The mare: a 1000-pound guinea pig for study of the ovulatory follicular wave in women.
Theriogenology, 77:818-828.

Goudet G, Bézard J, Duchamp G, Palmer E. 1997. Transfer of immature oocytes to a preovulatory follicle: an alternative to in vitro maturation in the mare? Equine Vet J Suppl, 29:54-59.

Haas CS, Rovani MT, Oliveira FC, Vieira AD, Bordignon V, Gonçalves PBD, Ferreira R, Gasperin BG. 2016. Expression of growth and differentiation Factor 9 and cognate receptors during final follicular growth in cattle. Anim Reprod, 13:756-761.

Hatzirodos N, Irving-Rodgers HF, Hummitzsch K, Harland ML, Morris SE, Rodgers RJ. 2014. Transcriptome profiling of granulosa cells of bovine ovarian follicles during growth from small to large antral sizes. BMC Genomics, 15:24.

Hunzicker-Dunn M, Maizels ET. 2006. FSH signaling pathways in immature granulosa cells that regulate target gene expression: Branching out from protein kinase A. Cell Signal, 18:1351-1359.

Ilha GF, Rovani MT, Gasperin BG, Antoniazzi AQ, Goncalves PB, Bordignon V, Duggavathi R. 2015. Lack of FSH support enhances LIF-STAT3 signaling in granulosa cells of atretic follicles in cattle. Reproduction, 150:395-403.

Jaiswal RS, Singh J, Adams GP. 2004. Developmental pattern of small antral follicles in the bovine ovary. Biol Reprod, 71:1244-1251

Jaiswal RS, Singh J, Adams GP. 2009. Highresolution ultrasound biomicroscopy for monitoring ovarian structures in mice. Reprod Biol Endocrinol, 7:69.

Juengel JL, Garverick HA, Johnson AL, Youngquist RS, Smith MF. 1993. Apoptosis during luteal regression in cattle. Endocrinology, 132:249-254.

Kassens A, Held E, Salilew-Wondim D, Sieme H, Wrenzycki C, Tesfaye D, Schellander K, Hoelker M. 2015. Intrafollicular oocyte transfer (IFOT) of abattoirderived and in vitro-matured oocytes results in viable blastocysts and birth of healthy calves. Biol Reprod, 92:150.

Komar CM, Berndtson AK, Evans AC, Fortune JE. 2001. Decline in circulating estradiol during the periovulatory period is correlated with decreases in estradiol and androgen, and in messenger RNA for $\mathrm{p} 450$ aromatase and p450 17alpha-hydroxylase, in bovine preovulatory follicles. Biol Reprod, 64:1797-1805

Kot K, Gibbons JR, Ginther OJ. 1995. A technique for intrafollicular injection in cattle: effects of hCG. Theriogenology, 44:41-50.

Li Q, Jimenez-Krassel F, Ireland JJ, Smith GW. 2009. Gene expression profiling of bovine preovulatory follicles: gonadotropin surge and prostanoid-dependent up-regulation of genes potentially linked to the ovulatory process. Reproduction, 137:297-307.

Lv L, Jimenez-Krassel F, Sen A, Bettegowda A, Mondal M, Folger JK, Lee K-B, Ireland JJ, Smith GW. 2009. Evidence supporting a role for cocaine- and amphetamine-regulated transcript (CARTPT) in control of granulosa cell estradiol production associated with dominant follicle selection in cattle. Biol Reprod, 81:580-586.

Matzuk MM, Burns KH, Viveiros MM, Eppig JJ. 
2002. Intercellular communication in the mammalian ovary: oocytes carry the conversation. Science, 296:2178-2180.

Menon B, Sinden J, Franzo-Romain M, Botta RB, Menon KMJ. 2013. Regulation of LH receptor mRNA binding protein by miR-122 in rat ovaries. Endocrinology, 154:4826-4834.

Mihm M, Baker PJ, Ireland JL, Smith GW, Coussens PM, Evans AC, Ireland JJ. 2006. Molecular evidence that growth of dominant follicles involves a reduction in follicle-stimulating hormone dependence and an increase in luteinizing hormone dependence in cattle. Biol Reprod, 74:1051-1059.

Ohtani M, Kobayashi S, Miyamoto A, Hayashi K, Fukui Y. 1998. Real-time relationships between intraluteal and plasma concentrations of endothelin, oxytocin, and progesterone during prostaglandin F2alphainduced luteolysis in the cow. Biol Reprod, 58:103-108.

Pépin D, Vanderhyden BC, Picketts DJ, Murphy BD. 2007. ISWI chromatin remodeling in ovarian somatic and germ cells: revenge of the NURFs. Trends Endocrinol Metab, 18:215-224.

Peters MW, Pursley JR, Smith GW. 2004. Inhibition of intrafollicular PGE2 synthesis and ovulation following ultrasound-mediated intrafollicular injection of the selective cyclooxygenase-2 inhibitor NS-398 in cattle. J Anim Sci, 82:1656-1662.

Richards JS. 1975. Estradiol receptor content in rat granulosa cells during follicular development: modification by estradiol and gonadotropins. Endocrinology, 97:1174-1184.

Richards JS, Hedin L. 1988. Molecular aspects of hormone action in ovarian follicular development, ovulation, and luteinization. Annu Rev Physiol, 50:441463.

Rivera GM, Fortune JE. 2001. Development of codominant follicles in cattle is associated with a follicle-stimulating hormone-dependent insulin-like growth factor binding protein-4 protease. Biol Reprod, 65:112-118.

Rosa P, Dau A, De Cesaro MP, Dos Santos JT, Gasperin BG, Duggavathi R, Bordignon V, Goncalves P. 2016. Mechanistic target of rapamycin is activated in bovine granulosa cells after LH surge but is not essential for ovulation. Reprod Domest Anim, 51:766-773.

Rovani M, Gasperin B, Ilha G, Ferreira R, Bohrer R, Duggavathi R, Bordignon V, Goncalves P. 2014. Expression and molecular consequences of inhibition of estrogen receptors in granulosa cells of bovine follicles. J Ovarian Res, 7:96.

Sahmi F, Nicola ES, Zamberlam GO, Gonçalves PDB, Vanselow J, Price CA. 2014. Factors regulating the bovine, caprine, rat and human ovarian aromatase promoters in a bovine granulosa cell model. Gen Comp Endocrinol, 200:10-17.

Sanchez R, Schuermann Y, Gagnon-Duval L, Baldassarre H, Murphy BD, Gevry N, Agellon LB,
Bordignon V, Duggavathi R. 2014. Differential abundance of IGF1, bile acids, and the genes involved in their signaling in the dominant follicle microenvironment of lactating cows and nulliparous heifers. Theriogenology, 81:771-779.

Santos JT, Ferreira R, Gasperin BG, Siqueira LC, de Oliveira JF, Santos RA, Reis AM, Gonçalves PB. 2011. Molecular characterization and regulation of the angiotensin-converting enzyme type 2/Angiotensin-(17)/MAS receptor axis during the ovulation process in cattle. J Renin Angiotensin Aldosterone Syst, 13:91-98.

Sartori R, Fricke PM, Ferreira JCP, Ginther OJ, Wiltbank MC. 2001. Follicular deviation and acquisition of ovulatory capacity in bovine follicles. Biol Reprod, 65:1403-1409.

Shirasuna K, Watanabe S, Oki N, Wijayagunawardane MPB, Matsui M, Ohtani M, Miyamoto A. 2006. A cooperative action of endothelin1 with prostaglandin F2 $\alpha$ on luteal function in the cow. Domest Anim Endocrinol, 31:186-196.

Shirasuna K, Akabane Y, Beindorff N, Nagai K, Sasaki M, Shimizu T, Bollwein H, Meidan R, Miyamoto A. 2012. Expression of prostaglandin F2 $\alpha$ (PGF2 $\alpha$ ) receptor and its isoforms in the bovine corpus luteum during the estrous cycle and PGF2 $\alpha$-induced luteolysis. Domest Anim Endocrinol, 43:227-238.

Silva J, Price C. 2000. Effect of follicle-stimulating hormone on steroid secretion and messenger ribonucleic acids encoding cytochromes P450 aromatase and cholesterol side-chain cleavage in bovine granulosa cells in vitro. Biol Reprod, 62:186-191.

Singh J, Pierson RA, Adams GP. 1998. Ultrasound image attributes of bovine ovarian follicles and endocrine and functional correlates. J Reprod Fertil, 112:19-29.

Siqueira LC, Oliveira JF, Rovani MT, Ferreira R, Borges LF, Gonçalves PB. 2009. Effects of estradiol and progestins on follicular regression before, during, and after follicular deviation in postpartum beef cows. Theriogenology, 71:614-619.

Siqueira LC, Barreta MH, Gasperin B, Bohrer R, Santos JT, Junior JB, Oliveira JF, Gonçalves PB. 2012. Angiotensin II, progesterone, and prostaglandins are sequential steps in the pathway to bovine oocyte nuclear maturation. Theriogenology, 77:1779-1787.

Spricigo JF, Netto SB, Muterlle CV, Rodrigues SA, Oliveira Leme L, Guimaraes AL, Caixeta FM, Franco MM, Pivato I, Dode MA. 2016. Intrafollicular transfer of fresh and vitrified immature bovine oocytes. Theriogenology, 86:2054-2062.

Valdez KE, Cuneo SP, Turzillo AM. 2005. Regulation of apoptosis in the atresia of dominant bovine follicles of the first follicular wave following ovulation. Reproduction, 130:71-81.

Vassena R, Mapletoft R, Allodi S, Singh J, Adams G. 2003. Morphology and developmental competence of bovine oocytes relative to follicular status. Theriogenology, 60:923 - 932. 